\title{
Generic frames and tonality: Mapping a polarizing issue in a multifaceted context
}

\author{
Ali Asker, Guenduez ${ }^{1 *}$, Kuno Schedler ${ }^{1}$, Dumitru, Ciocan ${ }^{2}$ \\ 1: University of St.Gallen, Switzerland \\ 2: University of Zurich, Switzerland \\ *: E-Mail to: aliasker.guenduez@unisg.ch
}

This is the preprint of an article published by Sage in European Journal of Communication on September 13, 2016, available online at: http://journals.sagepub.com/doi/abs/10.1177/0267323116666478
We highly recommend readers to access the final published and Accepted Manuscript referred to in the link above.

Citation: Guenduez, A. A., Schedler, K., \& Ciocan, D. (2016). Generic frames and tonality: Mapping a polarizing issue in a multifaceted context. European Journal of Communication, 31(5), 584-599. doi:10.1177/0267323116666478 


\begin{abstract}
This study explores the feasibility and usefulness of five generic frames (conflict, responsibility, economic consequences, human interest and morality) in analyzing framing practices in a multifaceted journalistic field over time. We show that supplementing generic frames through the tonality expressed in news stories enhances analytical quality. Mapping Swiss media outlets by how they frame a highly polarizing policy, we identify different framing practices in covering the issue. Using multiple correspondence analyses, the results first show that, while cultural background and media partisanship lead to heterogeneity in how the issue is initially framed, the state's involvement homogenizes framing practices over time. Second, unlike previous research, our study provides empirical evidence that both conflict frame and attribution of responsibility frame can measure the same underlying construct. Third, we find evidence that these two frames are strongly associated with a negative tone. Limitations and implications for future research are discussed.
\end{abstract}

Keywords: generic frames, tonality, culture, partisanship, journalistic framing practices, Switzerland 


\section{Introduction}

In the aftermath of the 2008 financial crisis, many governments, especially in Europe and the United States, began to scrutinize the Swiss banking sector, due to its status as tax haven. International pressure intensified both economically and politically. The Swiss response was the so-called "clean money policy": committing banks to manage only properly taxed foreign assets. Since this constituted a radical change in banking policy, this polarizing issue resonated strongly in the media. Massive international pressure on Swiss bank secrecy coupled with heated internal political debate - generated much political and economic uncertainty in the banking sector. As a result, the Swiss Federal Council attempted to refine and institutionalize this policy. In February 2012, the Swiss Federal Government released a first discussion paper and, in December 2012, an improved policy elaborating new due diligence rules for the Swiss banking sector. However, while making progress on paper, the Swiss Federal Government failed to implement the new policy and put it "on ice" by the end of 2013, awaiting the development of a binding international standard.

The question of how the media reports on an issue is central to framing research (Stromback \& Nord, 2006). This study investigates the question in a very multifaceted Swiss journalistic field. No national media exists in Switzerland; media in the German-, Frenchand Italian-speaking regions are characterized by strong cultural differences and a mutual cultural ignorance (Erk, 2003; Tresch, 2009). This heterogeneity manifests itself not only culturally, but also through the partisanship of the Swiss press (Blum, 2005; Haenggli \& Kriesi, 2010; Hallin \& Mancini, 2004). As a consensus-type democracy, the Swiss political system represents the linguistic/cultural and ideological/political diversity in a grandcoalition government (Linder, 2010). Following previous research (Benson, 1999; Benson \& Saguy, 2005; Cook, 1998; Kaplan, 2002; Sparrow, 1999), we consider the government to be a highly relevant actor influencing the framing practices in this multifaceted context. 
We investigate the use of generic frames in the Swiss press to pick up political/ideological, linguistic/cultural and temporal variations in news stories on the clean money policy. In addition, by examining the tonality of news stories, we gain a deeper understanding on how framing varies across different media outlets when debating a polarizing national policy. We use multiple correspondence analyses to visualize our findings and believe that the unique setting of this study contributes new insights to relevant communication research.

\section{Media Framing}

Frames are "constructions of the issue: they spell out the essence of the problem, suggest how it should be thought about" (Nelson \& Kinder, 1996, p. 1057) and are "central organizing idea[s] ... for making sense of relevant events, suggesting what is at issue" (Gamson \& Modigliani, 1989, p. 3). To frame an issue means to "select some aspects of a perceived reality and make them more salient in a communication text" (Entman, 1993, p. 52). Scholars differentiate between issue-specific and generic frames (de Vreese, Peter, \& Semetko, 2001; Lecheler, de Vreese, \& Slothuus, 2009; Semetko \& Valkenburg, 2000). They can be seen as complementary layers of framing (Brueggemann, 2014). While issue-specific frames typically pertain to certain issues, "generic frames are broadly applicable to a range of different news topics, some even over time and, potentially, in different cultural contexts" (de Vreese, Peter, \& Semetko, 2001, p. 108).

In this study, we focus on generic frames. Brueggemann (2014) describes them as "typical structures of issue specific frames". They constitute specific layers of contextualization in stories that cover and amplify a desired perspective and can be regarded as compounded patterns of meaning articulated in news content (Brueggemann, 2014). A generic approach allows investigations and comparisons of these compounded discourses and journalistic contextualization in news framing over time. Semetko and Valkenburg (2000), in 
their seminal work, specify five types of generic frames: conflict, attribution of responsibility, economic consequences, human interest and morality. This study will analyze framing practices by employing these generic frames. The rationale for our choice is pragmatic; in contrast to other studies applying generic frames (e.g., Cappella \& Jamieson, 1996; Iyengar, 1991), Semetko and Valkenburg (2000) offer a broader set of frames, accompanied by clear and concise operationalization of the theoretical constructs. Furthermore, these frames can not only pick up political, cultural and temporal variations in news stories, but also relate to at least three main aspects of the pertinent issue: conflict stemming from the international pressure, economic consequences for the Swiss banking sector and the government's responsibility to provide a solution.

According to Baumgartner and Jones (1991), media coverage of an issue has two dimensions: attention and valence. While attention is closely linked to the frames' salience, valence specifies the frames' tonality. Framing literature treats valence as an inherent normative aspect of journalistic framing (e.g., Chong \& Druckman, 2007; de Vreese \& Boomgaarden, 2003; de Vreese \& Boomgaarden, 2006; Maier \& Rittberger, 2008). Journalists emphasize the tonality of a frame by portraying an issue in terms of good or bad news. In this regard, de Vreese and Boomgaarden (2003) state that some frames are inherently valenced. According to the authors, valenced frames such as 'Cold War' or 'Democracy' indicate either positive or negative tone, while others, such as the 'conflict frame', suggest a more neutral tone. To the best of our knowledge, few studies have used valence in conjunction with generic frames (e.g., Lecheler et al., 2009; Lecheler \& de Vreese, 2013). Therefore, we include tonality in our analysis.

\section{Framing of a polarizing Issue in a multifaceted Context}

Press coverage is shaped by culture in any national context. Scholars emphasize cultural differences when analyzing press coverage of a given issue (Benson, 2004; e.g., 
Benson \& Saguy, 2005; Saguy, 2002). However, this body of empirical research is largely based on cross-national comparison; we use this approach, but consider different cultural areas within one country. As Erk (2003) specifies, a national media does not exist in Switzerland. Media in the German-, French- and Italian-speaking regions are characterized by different readerships and issue coverage. This linguistic segmentation comes along with a cultural divide. As a consequence, one can almost speak of three different public spaces within Switzerland, where journalists reflect the norms and values of the cultural area in which they are embedded (Erk, 2003; Hallin \& Mancini, 2004; Tresch, 2009). With regards to foreign policy, scholars emphasize a prevailing national conservatism in the German part of Switzerland, while the French-speaking Swiss area stands out for its international openness (Trechsel, 1995; Vatter, 1994). As argued by Tresch (2009), national conservatism is also the norm for newspapers in German. The Swiss Italian region is concentrated in the southern canton of Ticino, with the media in this smaller area dominated by the German and the French counterparts. Following the notion that culture is "embedded in media content during the frame process" (Van Gorp, 2007, p. 64), we expect significant cultural differences in issue framing. To begin, in a tense situation such as this, parties are - by definition - in conflict with each other, giving the media reasons to use conflict and responsibility frames more than others (Semetko \& Valkenburg, 2000). Additionally, most conflicts are, at least latently, solution-oriented and justified with consequences. Given international pressure coupled with dreaded potential economic consequences - we expect three generic frames to be most salient in news stories: conflict, responsibility and economic consequences (hypothesis 1). Considering foreign coercive pressures, we expect conflict and responsibility frames to be more salient in the culturally conservative area, while the economic consequences frame is expected to be more salient in the area characterized by international openness (hypothesis 1a). Additionally, we expect the tonality of the articles to be more 
negative in the former area and more positive in the latter (hypothesis 1b). Moreover, within a national context where two bigger cultural areas dominate a third, the media of this smaller cultural area are expected to take the middle ground, thus employing a more balanced mix of frames and tonalities in their articles (hypothesis 1c).

Culture, however, is not the sole source of divergence. Differences also stem from the tendency to reflect major political divisions. Switzerland has a wide range of political parties and ties between news outlets and political parties have grown historically. During the last decades, Swiss press partisanship diminished steadily (Blum, 2005; Haenggli \& Kriesi, 2010; Hallin \& Mancini, 2004).However informal ties between press and parties still induce outlets to prefer frames close to the their political values (Haenggli \& Kriesi, 2010). Particularly polarizing issues like climate change, abortion, or gun control act as catalysts for oppositional interpretations when partisan tendencies exist in the media (Brueggemann, 2014). In Switzerland, issues relating to international openness are highly controversial and cause serious divisions within the party system (Sciarini \& Tresch, 2009). The left-wing Social Democratic Party advocates universalism and international openness. In contrast, the conservative right Swiss People's Party defends a particularistic view and constantly opposes international openness. The more moderate right parties, such as Christian Democrats, Conservative Democrats and Liberals take more nuanced positions in foreign policy debates (Fossati \& Haeusermann, 2014). Given the polarizing nature of the issue at stake, we expect partisanship to influence outlets' framing choices (hypothesis 2). More specifically, we expect the conservative right parties to have a negative attitude towards this issue and the right-wing media to reflect this attitude by covering the issue with a predominantly negative tone, irrespective of the frames (hypothesis 2a). In contrast, we expect the left-leaning parties to have a positive attitude towards this issue and the left-liberal news outlets to reflect this attitude by covering the issue with a predominantly positive tone (hypothesis $2 \mathrm{~b}$ ). As for the 
more moderate parties, we expect them to have more moderate attitudes toward the issue and news outlets belonging to the center and right-liberal to use tonalities more ambivalently (hypothesis 2c).

Going one step further, we include the Swiss government as an additional political actor. Many scholars consider the state to be one of those forces shaping the media, as well as journalistic production and practices (Cook, 1998; Kaplan, 2002; Sparrow, 1999). Gerth and Siegert (2012) as well as Haenggli (2012) document the role of these actors during campaigns Switzerland. Considering that a "frame in communication can be defined only in relation to a specific issue, event, or political actor" and that the "same issue at different times can invoke alternative frames"(Chong and Druckman 2007, p. 106), we investigate how the government's involvement - after February 2012 - influenced Swiss press framing choices. Following this, we shift to a more process-oriented perspective. Framing, in this sense, is a dynamic process through which journalists change their framing choices by bringing novel aspects of an issue into the foreground, while pushing former aspects into the background (Lecheler \& de Vreese, 2011). Taking the increased state involvement after February 2012 into account, we expect a shift in framing choices toward a greater focus on political aspects of the issue, while economic considerations are pushed into the background (hypothesis 3). More specifically, we expect that the more the journalists orient themselves towards a politics criteria, the greater the prevalence of conflict and responsibility frames (hypothesis 3a). [Furthermore, due to the lack of legitimation and institutionalization of the new policy in real life], we expect an increase in more critical reporting and thus, an overall negative tone in news stories in this later period (hypothesis 3b). After February 2012, we should observe a high degree of homogenization in issue coverage, irrespective of culture or press partisanships (hypothesis 3c). 


\section{Methods}

The data are derived from a content analysis of 1175 news stories published from February 2008 to September 2013 in the Swiss press. Switzerland has four official languages: German (64.5\%), French (22.6 \%), Italian (8.3\%) and Rhaeto-Romanic (0.5\%). We identified newspapers and magazines published in the three most widely spoken languages and selected those with the highest circulation rates in each language group. This led to the selection of four newspapers (Neue Züricher Zeitung, Tages Anzeiger, Neue Luzerner Zeitung and Blick) and three magazines (Die Weltwoche, Finanz und Wirtschaft and Handelszeitung) in German, three newspapers (Tribunde de Genève, 24Heures and Le Matin) and two magazines (L'Hebdo and L'Agefi) in French and two newspapers (Corriere del Ticino and La Regione Ticino) in Italian. Swiss magazines in Italian were not available from our databases. News stories in German and French were obtained from the Factiva database and Italian ones from the Archivio digitale Sbt dei Quotidiani e Periodici. Relevant articles were identified using the keywords "Weissgeld" for German, "l'argent proper/blanc" for French and "fondi dichiarati" and "denaro pulito" for the Italian outlets. Assuming the same level of salience of the issue across these three cultural regions, the article selection is highly representative: $69.9 \%$ of articles are in German, $22.7 \%$ in French, and 7.4\% in Italian.

The unit of analysis is a news story dealing with clean money policy. A team of three coders was trained and supervised, each coder fluent in at least two relevant languages. The codebook was repeatedly pretested on randomly selected articles. The inter-coder reliability on a randomly selected sample of 50 articles yielded Krippendorf's Alpha ranging from 0.68 up to 0.87 for the coded items.

We operationalize the partisanship of the Swiss media using Blum's (2005) categorization and differentiate between right (Weltwoche), right-liberal (Neue Zürcher Zeitung, Neue Luzerner Zeitung and Corriere del Ticino), center (Le Matin) and left-liberal 
oriented publications (Tages Anzeiger, 24Heures, L'Hebdo, Tribune de Genève, La Regione Ticino and Blick).

We adopt the conceptualization and operationalization of the five generic frames as developed by Semetko and Valkenburg (2000). The attribution of responsibility frame is operationalized using five items coding: the ability of the government to deal with the problem (R1), responsibility for the problem being held by the government (R2) or some other actor (R4), discussion of solutions to the problem (R3) and the urgency of taking action (R5). The conflict frame codes whether the story mentions that an actor disagrees with (C1) or reproaches another $(\mathrm{C} 2)$, it implies that there are more than two sides to the problem $(\mathrm{C} 3)$, or it refers to winners and losers (C4). Mentions of financial gains or losses (E1), costs or expenses (E2) and, more generally, references to economic consequences of pursuing some course of action or not (E3) are used to code the economic consequences frame. The morality frame codes whether the news story contains a moral message (M1), reference to religious tenets (M2) or other prescriptions about how to behave (M3). The human interest frame codes whether the news story evokes emotional feelings by providing a human example (H1), by employing adjectives (H2), by emphasizing how individuals are affected by the problem (H3) or by relating other private or personal information about actors' lives (H4). A fifth item belonging to the human interest frame from the original item battery by Semetko and Valkenburg (2000), could not be included since our databases do not provide visual information. All items are coded as 1 when the news story provides affirmative answers and as 0 otherwise.

We follow the recommendations of Lengauer, Esser and Berganza (2012) and differentiate between positive, negative, neutral and ambivalent tonality. A news story has a negative tonality when the story reflects indications ranging from disappointment, frustration, skepticism, threat and risk up to political failure, crisis and disaster. Indications of positive 
tonality range from hope and enthusiasm up to solutions, successes and gains. A news story has an ambivalent tonality when it balances elements of negative and positive tonalities and a neutral tonality when it reflects neither negative nor positive views.

Following Sciarini and Tresch (2009) we consolidate the ruling political parties on the political spectrum into three camps: the conservative right (Swiss People's Party), the moderate right (Christian Democratic, Liberal and Conservative Democratic Party) and the left (Social Democratic Party). The attitude variable codes statements of these ruling Swiss parties in our dataset and differentiates between negative (rejecting the clean money policy), positive (advocating the clean money policy) and ambivalent (co-occurrence of negative and positive statements) attitudes. We differentiate between the Italian, French and German cultural areas using the language of the news story, since differences between these linguistic-cultural areas have been documented by studies such as Kriesi (1992), Erk (2003) and Tresch (2009).

We employ multiple correspondence analyses (MCA) to visualize our findings. MCA is a data analysis technique designed for nominal categorical variables, much the same way as principal component analysis (PCA) is for continuous variables. It identifies the underlying structure of a dataset and reduces it to "principal dimensions [which] capture the most variance possible, allowing for lower-dimensional descriptions of the data" (Greenacre and Blasius, 2006, p. 6). Using these dimensions as axes in two-dimensional graphs, MCA can project the categories of variables according to their contribution on each dimension, thus visualizing the relationships between variables. Generally, the geometric distance between two projections denotes the strength of their relationship: the smaller the distance, the stronger the relationship. To provide an objective measure of the relationship strength discussed, we also report chi-square values, since MCA is rooted in chi-square calculations. We discern between active variables, which contribute to determining these dimensions (i.e., 
items of the generic frames) and supplementary variables, which do not (i.e., all other variables). Supplementary variables are also projected in this space, since they "support and complement the interpretation of the configuration of active variable categories" (Greenacre \& Blasius, 2006, p. 31). Note that we will forgo discussing distances between categories of distinct supplementary variables, as these do not entail information on the strength of their relationship.

\section{Results}

\section{Dimensions of the issue coverage}

In a first step, we performed a MCA for each generic frame separately to determine whether the constituent items of a generic frame do indeed describe a single dimension and that the contribution of each item is significant. Four items are problematic and have been removed from the subsequent analyses. More precisely, the items R4, R5, C4 and H4 all contribute primarily to secondary dimensions, indicating that they capture some other aspect than the intended underlying construct. Previous research has already identified three of these items (i.e., R4, R5 and C4) as problematic (Semetko and Valkenburg, 2000; Igartua, Cheng and Muniz, (2005). We exclude the four items from the subsequent analysis and retain exactly three items per generic frame. The reliability test yielded Cronbach's Alpha values of 0.81 for conflict, 0.79 for responsibility, 0.71 for morality, 0.69 for economic consequence and 0.64 for human interest frame.

In a second step, we use these fifteen items as active variables in our MCA. The analysis reduces these items to five dimensions, which explain $75.3 \%$ of the total variance. Figure 1 shows the results for the first two dimensions only, the first dimension (x-axis) explaining $47.1 \%$ of the variance, while the second dimension (y-axis) explains another $12.4 \%$. 
$>$ Figure $1<$

The items of the generic frames are represented graphically by colored triangles, while each category of supplementary variables is represented by dots for outlets, rhombs for cultural areas and squares for tonality. Figure 1 shows that items belonging to the same generic frame cluster close together. However, it also indicates that items of conflict and responsibility frames are also strongly associated with one another, since they cluster together on the horizontal axis. These results imply that these six items actually describe only a single frame. This is very interesting and unexpected, given that previous research (e.g., Neuman, Just, \& Crigler, 1992; Semetko \& Valkenburg, 2000) treat conflict and responsibility frames as conceptually distinct. Given the nature of the items defining this first dimension, we label this axis the political dimension. The positive (right) side of this dimension shows outlets relying heavily on the conflict and responsibility frames, while the negative (left) side shows outlets avoiding these two frames. The second dimension differentiates similarly in the use of the economic consequences frame. The relevance of conflict, responsibility and economic consequences frames in defining the main dimensions of our MCA confirms our first hypothesis (H1).

\section{Cultural-Linguistic Influences}

Positions of cultural areas relative to dimensions in Figure 1 indicate that outlets of these areas use the five generic frames to different degrees, since each inhabits a different quadrant of our map. They are, however, relatively close to each other. A chi-square test of independence between cultural areas and frame usage was performed. For this, we consider a frame to be present in a news story if - and only if - all three items are present and news stories may contain any combination of the responsibility, conflict and economic consequences frames. This test confirms that the observed distances are indeed relevant; the relationship is statistically significant with $X^{2}(14,1175)=63,18, p<0.001$. The graph shows 
that the conflict and responsibility frames are indeed more salient for the German cultural area than for the French one, while the opposite is true for the economic consequences frame. These results strongly support our hypothesis H1a. As expected in H1b, compared to the French outlets, German publications such as Weltwoche, Handelszeitung and Blick are leaders when it comes to framing their news stories negatively $(60 \%, 47 \%$ and respectively $39 \%$ ), while those in the French area use a much more neutral tone (L'Hebdo 56\%, L'Agefi $51 \%$ ). Furthermore, our map shows that tonality spreads mainly along the political dimension; the neutral and positive tonalities position themselves on the negative side, while the ambivalent and negative ones position themselves on the positive side of this dimension. The negative tonality is closest to the positive extremes of the political dimension, which implies that framing the issue negatively is strongly associated with employing the conflict and responsibility frames and, at the same time, indicates a close relationship to outlets in German. On the other side, framing the issue neutrally is associated with more sparing use of these two frames and indicates a close relationship to outlets in French and Italian. By framing the issue neutrally and employing less conflict and responsibility frames, outlets of the French and Italian areas distance themselves strongly from their German counterparts. Taking a closer look at Italian publications, results support our expectations about the moderate usage of generic frames relative to both other cultural areas (H1c). The outlets in Italian score similar to those in French on the political dimension and similar to those in German on the economic dimension, as shown in Figure 1. Moreover, La Regione Ticino is closest to the intersection of the two dimensions, which indicates that this newspaper is the most balanced of our dataset. We also find that Italian publications frame news stories positively as often as they do neutrally. These results support our expectation on the moderate use of tonality. 


\section{Political-ideological Influences}

Journalistic framing practices are affected not only by culture, but also by individual outlets' partisanship. Our map shows that the right-oriented outlet Weltwoche inhabits the outer edge of the upper right quadrant. Even though Blum (2005) characterizes the newspaper Blick as being left-liberal, in our analysis Blick is the closest neighbor of Weltwoche, showing framing practices most similar to this right-wing oriented publication. This result might be explained by Blick's right-shift over the last twenty years. Due to this shift, Blick has been treated - in our analysis - as a right-wing oriented outlet, along with Weltwoche. Other outlets show more diverse framing repertoires with subtle differences; notable variances are, however, seen in the right-liberal oriented outlets Neue Zürcher Zeitung, Corriere del Ticino and Neue Luzerner Zeitung. These newspapers are very similar to each other in their positioning on the negative side of the economic dimension, but differ in the political dimension. The left-liberal newspapers are even more dispersed, on our map, and distance themselves from one another along both dimensions. This is not surprising, given that most Swiss newspapers fall into this category and that, consequently, competition among them is more intense. More precisely, right-liberal newspapers stretch across both lower quadrants of our map, while left-liberal outlets inhabit all but the lower left quadrant of our map. The left-liberal newspapers Tages Anzeiger, La Regione Ticino, L’Hebdo, 24Heures and Tribune de Geneve are slightly more similar in the political than in the economic dimension. The lower right quadrant of our map is occupied by both a right-liberal and a left-liberal newspaper, The Neue Luzerner Zeitung and the Tages Anzeiger. Their close proximity indicates that framing practices are almost identical. Furthermore, they closely resemble the framing practices of the sole 'middle' representative, Le Matin. We performed a chi square test of independence to investigate whether these relationships are statistically significant; they are indeed, with the relationship between frames and partisanship $X^{2}(14$, 
$\mathrm{N}=889)=42,79$ and $\mathrm{p}<0.001$. Moreover, we find that there is a statistically significant relation between partisanship of the outlets and the political parties mentioned in news stories; the chi square value is $\mathrm{X}^{2}(14, \mathrm{~N}=889)=55,18$ and $\mathrm{p}<0.001$. These results strongly support our overall hypothesis $\mathrm{H} 2$.

Taking a closer look at the relationship between the tonality employed by the two right-oriented outlets and the conservative Swiss People's Party attitude, we also find strong support for our hypotheses H2a. Our results show that clean money policy is discussed in Blick and Weltwoche with a predominantly negative tonality, in $44.8 \%$ of their news stories. This is significantly higher than for left-liberal (27.9\%) and right-liberal (34.3\%) oriented outlets. This negative framing also corresponds with the clearly negative attitude of the conservative Swiss People's Party; in $91.5 \%$ of all instances, it takes a negative position on the issue of the clean money policy (see Table 1).

$>$ Table $1<$

The hypothesis $\mathrm{H} 2 \mathrm{~b}$ is, however, not clearly substantiated by our data. It was expected that left-liberal outlets would employ a more positive tonality in their news stories, which would, in turn, correspond with a more positive stance of the Social Democrats towards the issue at stake. We find some support for this hypothesis. For example, $\mathrm{La}$ Regione Ticino is the most positive outlet on the issue, showing a positive tonality in $35.1 \%$ of its news stories. Correspondingly, the Social Democratic Party supports the policy in $48.6 \%$ of its statements, while it opposes the policy in only $18.3 \%$ of their statements. However, contrary to our expectations, we find that left-liberal outlets in general employ a neutral tonality $(40.9 \%)$ more often than a positive (19.9\%). Furthermore, results show that the Conservative Democratic Party also takes a positive stance at least as often as the Social Democratic Party (48,7\%). Its strong support might be explained by the fact that the finance 
minister in charge of formulating the clean money policy belongs to the Conservative Democratic Party.

Hypothesis H2c is also only partly supported by our data. The moderate parties show a high percentage of ambivalent stances toward the policy, as shown in Table 1. The Liberal Party is ambivalent in its statements in $45.8 \%$ of all cases, while the Christian Democratic Party and the Conservative Democratic Party are ambivalent in $24.4 \%$ and $19.4 \%$ of the cases. Corresponding publications, on the other hand employ predominantly neutral and negative tonalities in their news stories, $35.9 \%$ and $32.7 \%$, with positive and ambivalent tonality in $19.9 \%$ and respectively $11.5 \%$ of their news stories. Thus, center and right-liberal oriented outlets do not reflect the predominantly ambivalent stance of the moderate right parties on this issue in their reporting.

\section{State Influences}

Finally, we turn to the dynamic modeling of framing practices. To analyze how the government's involvement on the issue influenced framing practices over time (H3), we distinguish between two periods separated by the state's definition of the measures behind the clean money policy on February 2012. The two periods differentiate between a debate focusing on the necessity of a clean money policy and one focusing on its implementation. Figure 2 present the results of our dynamic correspondence analysis.

$>$ Figure $2<$

As evidenced by Figure 2, framing practices differ quite significantly during these two time periods. The shifts in framing practices from the first period to the second are indicated by arrows. In line with our expectation (H3a), most cases in this dynamic correspondence map shift much more strongly along the political dimension than the economic, indicating increased salience of items in the political dimension during the later period. In 10 of the 14 cases, we see a clear shift towards the positive side of the political dimension. Two others 
(Handelszeitung and 24Heures) shift only marginally along the political dimension and just two cases (Weltwoche and Corriere del Ticino) defy this trend. These four observations are, however, not of great significance, since they show the least change in their framing practices from one period to the next. The consistency can be explained neither by their cultural background nor by their partisanship. Comparing news stories' tonality during the two periods, we also confirm expectations about an overall negative tonality during the later period.

$>$ Table $2<$

As evidenced by Table 2, news stories before February 2012 are presented predominantly neutrally $(40.4 \%)$ and news stories with a positive tonality $(27,4 \%)$ outweigh the negative (18.4\%). During the second period, the issue is mainly covered using negative tonality $(41.5 \%)$, while the use of neutral $(32.7 \%)$, positive $(17.8 \%)$ and ambivalent $(8 \%)$ tonalities decrease significantly. These results strongly support our hypothesis H3b. The shift to the positive side of the political dimension (i.e., more conflict and responsibility frames) and its connection with the overall negative tone after the state involvement indicates a considerable homogenization in how the print media portrays this issue. These results strongly support our overall hypothesis $\mathrm{H} 3 \mathrm{c}$.

\section{Conclusion}

In this study, we examined the framing of a polarizing policy in the Swiss press. We presented a differentiated approach to comparative analysis of news framing by investigating debates on the same policy in relatively distinct regions within one country. Mapping the Swiss press by using MCA, this study tried to bring together cultural embeddedness of the press, their respective political orientations and journalistic framing practices over time. Generic frames have been applied in several cross-national comparative studies, such as de 
Vreese, Peter and Semetko (2001). The present study extends existing literature by simultaneously applying generic frames and tonality for the first time in a multifaceted national context. Taking advantage of the Swiss case where news organizations are differentiated by language and ideological orientations, we were able to provide evidence that journalistic framing practices are shaped by both cultural differences and political orientation. While linguistic/cultural and the ideological/political divisions lead to a heterogeneity in journalistic framing, our correspondence map based on two time periods shows that state involvement diminishes these differences and leads to a homogenization in how the print media chooses to portray the issue at stake.

The present study contributes to existing literature by linking generic frames to the relatively distinct regions within one country over time. In doing so, we could demonstrate the feasibility and usefulness of such an approach in generic frame research. Compared to issue frames, the use of generic frames can be limited by their generic nature. Use of generic frames certainly varies for different reasons and in different ways. Nevertheless, our study shows that generic frames are also capable of picking up political, cultural and temporal variation in news stories, which can all be seen as domains of issue specific frames.

In this study, we also provide evidence that cultural and partisan influences are present not only when using generic frames, but also in the tonality of the news stories. Though these findings are not always as clear-cut as hypothesized, one interesting aspect stands out when considering the shift toward conflict and responsibility frames and the corresponding shift in news stories' valence. Many scholars treat valance as an inherent aspect of journalistic framing (e.g., Chong \& Druckman, 2007; de Vreese \& Boomgaarden, 2003; de Vreese \& Boomgaarden, 2006; Maier \& Rittberger, 2008). De Vreese and Boomgaarden (2003), though, state that the conflict frame "may not necessarily offer specific evaluations on an issue" (p. 364). What we find contradicts this statement, at least in the 
present study's context. Our study provides empirical evidence that not only the conflict, but also the responsibility frame is strongly associated with a negative tone; their absence in news stories is strongly associated with a neutral tonality.

Our study contains three major implications for future research. A first implication relates to the generic frames and one of its basic assumptions. Since first introduced by Semetko and Valkenburg (2000), numerous researchers treat the five generic frames as intrinsically distinct constructs. Our study calls this basic assumption into question, since it provides a counter example where both the conflict and attribution of responsibility frames seem to measure the same underlying construct. We labeled this construct as political dimension. The MCA map indicates that items relating to the two frames are, in fact, so closely related that even the rotation of the solution, as routinely performed in PCA, could not influence our findings. This supports the conclusion that our results are not artifacts of this study's methodology (Campbell \& Fiske, 1959), bolstering our conviction that this is not an isolated case. It seems obvious that in a political conflict, competing possible solutions will be proposed; conflicts are also more likely over policy if government has a potential role in it. Thus, future research will need to enquire both on a theoretical and empirical basis when and why such frames overlap.

Second, as far as we know, this is the first study to analyze generic frames by employing MCA. By using generic frames as active variables and tonality as a supplementary variable, our methodological approach illustrates how different types of frames can be brought in relation to one another. This permits - for example - bridging generic and issue specific frames, allowing a more comprehensive understanding of a given issue. Further, by considering generic frames as a baseline and supplementing these with further elements like actors, norms, values, codes and beliefs, one can identify and visualize, through this 
approach, what Van Gorp (2007) calls a "frame package". We believe this line of inquiry has a great potential for generating new insights (cf., Meyer \& Hoellerer, 2010).

Third, taking advantage of the graphic options available with this method, we were able to visualize the hypothesized relationships. A case in point is the dynamic map showing changes in framing repertoires of the print media. While the majority of the outlets performed as we expected, four stand out in this map because they did not follow an overall trend. None of the considered variables can account individually or together for all four outlets. This finding represents an interesting line of enquiry for future research.

This study has several limitations as well; the first concerns the nature of the sample. Because we focused on print media and analyzed the framing of a particular issue in a particular national context, the results may not be generalizable to other media, issues or countries. Nevertheless, we believe that the findings are transferable to other similar linguistically divided geographical regions like Belgium, Estonia, Latvia, or Canada. A second limitation concerns the range of news outlets considered in this paper. Although our study includes a broad range of Swiss newspapers and magazines, our databases did not provide magazines in Italian. The third limitation concerns the nature of frames applied in this study. The generic frames, which span our map, can - by their very nature - capture only a small part of the variation within a news story. Indeed, researchers have pointed out this limitation by comparing generic frames to loose schemata, scripts, arguments or genres (e.g., Van Gorp, 2007; Vliegenthart \& van Zoonen, 2011). Complementing these frames with the tonality of the news story, we attempt to partially compensate for this limitation and allow a more detailed analysis of media framing repertoires. 


\section{References}

Baumgartner, F. R., \& Jones, B. D. (1991). Agenda Dynamics and Policy Subsystems. Journal of Politics, 53(4), 1044-1074.

Benson, R. (2004). Bringing the sociology of media back in. Political Communication, 21(3), 275-292.

Benson, R., \& Saguy, A. C. (2005). Constructing social problems in an age of globalization: A French-American comparison. American Sociological Review, 70(2), 233-259.

Blum, R. (2005). Politischer Journalismus in der Schweiz [Political journalism in Switzerland]. In P. Donges (Ed.), Politische Kommunikation in der Schweiz (pp. 115130). Bern: Haupt.

Brueggemann, M. (2014). Between Frame Setting and Frame Sending: How Journalists Contribute to News Frames. Communication Theory, 24(1), 61-82.

Campbell, D. T., \& Fiske, D. W. (1959). Convergent and discriminant validation by the multitrait-multimethod matrix. Psychological Bulletin, 56(2), 81-105.

Cappella, J. N., \& Jamieson, K. H. (1996). News frames, political cynicism, and media cynicism. Annals of the American Academy of Political and Social Science, 546, 7184.

Chong, D., \& Druckman, J. N. (2007). Framing theory. Annual Review of Political Science, 10, 103-126.

Cook, T. E. (1998). Governing with the News: The News Media as a Political Institution. Chicago: University of Chicago Press.

de Vreese, C. H., \& Boomgaarden, H. (2003). Valenced news frames and public support for the EU. Communications, 28, 361-381.

de Vreese, C. H., Peter, J., \& Semetko, H. A. (2001). Framing politics at the launch of the euro: A cross-national comparative study of frames in the news. Political Communication, 18(2), 107-122.

Entman, R. M. (1993). Framing - Toward Clarification Of A Fractured Paradigm. Journal of Communication, 43(4), 51-58.

Erk, J. (2003). Swiss federalism and congruence. Nationalism and Ethnic Politics, 9(2), 5074.

Fossati, F., \& Haeusermann, S. (2014). Social Policy Preferences and Party Choice in the 2011 Swiss Elections. Swiss Political Science Review, 20(4), 590-611.

Gamson, W. A., \& Modigliani, A. (1989). Media Discourse and Public-Opinion on NuclearPower - A Constructionist Approach. American Journal of Sociology, 95(1), 1-37.

Gans, H. (1979). Deciding what's news: A study of CBS Evening News, NBC Nightly News, Newsweek and TIME. New York, NY: Pantheon Books.

Gerth, M. A., \& Siegert, G. (2012). Patterns of Consistence and Constriction: How News Media Frame the Coverage of Direct Democratic Campaigns. American Behavioral Scientist, 56(3), 279-299.

Greenacre, M., \& Blasius, J. (2006). Multiple Correspondence Analysis and Related Methods. Boca Raton, FL: Chapman \& Hall.

Haenggli, R., \& Kriesi, H. (2010). Political Framing Strategies and Their Impact on Media Framing in a Swiss Direct-Democratic Campaign. Political Communication, 27(2), 141-157.

Haenggli, R. (2012). Key Factors in Frame Building: How Strategic Political Actors Shape News Media Coverage. American Behavioral Scientist, 56(3), 300-317. 
Hallin, D. C., \& Mancini, P. (2004). Comparing Media Systems. Three Models of Media and Politics (L. W. Bennet \& R. M. Entman Eds.). Cambridge: Cambridge University Press.

Igartua, J. J., Cheng, L., \& Muniz, C. (2005). Framing Latin America in the Spanish press: A cooled down friendship between two fraternal lands. Communications-European Journal of Communication Research, 30(3), 359-372.

Iyengar, S. (1991). Is Anyone Responsible? How Television Frames Political Issues. Chicago: University of Chicago Press.

Kaplan, R. L. (2002). Politics and the American Press: The Rise of Objectivity, 1865-1920. Cambridge: Cambridge University Press.

Kriesi, H. (1992). Öffentlichkeit und soziale Bewegung in der Schweiz - ein Musterfall? [Public and social Movement in Switzerland - an exemplar case] In B. Schäfer (Ed.), Lebensverhältnisse und soziale Konflikte im neuen Europa [Living conditions and social conflicts in the new Europe] (pp. 576-585). Frankfurt: Campus.

Lecheler, S., \& de Vreese, C. H. (2011). Getting Real: The Duration of Framing Effects. Journal of Communication, 61(5), 959-U248.

Lecheler, S., \& de Vreese, C. H. (2013). What a Difference a Day Makes? The Effects of Repetitive and Competitive News Framing Over Time. Communication Research, 40(2), 147-175.

Lengauer, G., Esser, F., \& Berganza, R. (2012). Negativity in political news: A review of concepts, operationalizations and key findings. Journalism, 13(2), 179-202.

Linder, W. (2010). Swiss democracy. Possible solutions to conflict in multicultural society (3 ed.). Basingstoke: Palgrave/Macmillan.

Baumgartner, F. R., \& Jones, B. D. (1991). Agenda Dynamics and Policy Subsystems. Journal of Politics, 53(4), 1044-1074. doi:10.2307/2131866

Benson, R. (1999). Field theory in comparative context: A new paradigm for media studies. Theory and Society, 28(3), 463-498. doi:10.1023/a:1006982529917

Benson, R. (2004). Bringing the sociology of media back in. Political Communication, 21(3), 275-292. doi:10.1080/10584600490481299

Benson, R., \& Saguy, A. C. (2005). Constructing social problems in an age of globalization: A French-American comparison. American Sociological Review, 70(2), 233-259.

Blum, R. (2005). Politischer Journalismus in der Schweiz [Political journalism in Switzerland]. In P. Donges (Ed.), Politische Kommunikation in der Schweiz (pp. 115130). Bern: Haupt.

Brueggemann, M. (2014). Between Frame Setting and Frame Sending: How Journalists Contribute to News Frames. Communication Theory, 24(1), 61-82. doi:10.1111/comt.12027

Campbell, D. T., \& Fiske, D. W. (1959). Convergent and discriminant validation by the multitrait-multimethod matrix. Psychological Bulletin, 56(2), 81-105. doi: $10.1037 / \mathrm{h} 0046016$

Cappella, J. N., \& Jamieson, K. H. (1996). News frames, political cynicism, and media cynicism. Annals of the American Academy of Political and Social Science, 546, 7184. doi:10.1177/0002716296546001007

Chong, D., \& Druckman, J. N. (2007). Framing theory. Annual Review of Political Science, 10, 103-126. doi:10.1146/annurev.polisci.10.072805.103054

Cook, T. E. (1998). Governing with the News: The News Media as a Political Institution. Chicago: University of Chicago Press.

de Vreese, C. H., \& Boomgaarden, H. (2003). Valenced news frames and public support for the EU. Communications, 28, 361-381. doi:10.1515/comm.2003.024 
de Vreese, C. H., \& Boomgaarden, H. G. (2006). Media effects on public opinion about the enlargement of the European Union. Jcms-Journal of Common Market Studies, 44(2), 419-436. doi:10.1111/j.1468-5965.2006.00629.x

de Vreese, C. H., Peter, J., \& Semetko, H. A. (2001). Framing politics at the launch of the euro: A cross-national comparative study of frames in the news. Political Communication, 18(2), 107-122. doi:10.1080/105846001750322934

Entman, R. M. (1993). Framing - Toward Clarification Of A Fractured Paradigm. Journal of Communication, 43(4), 51-58. doi:10.1111/j.1460-2466.1993.tb01304.x

Erk, J. (2003). Swiss federalism and congruence. Nationalism and Ethnic Politics, 9(2), 5074. doi:10.1080/13537110412331301415

Fossati, F., \& Haeusermann, S. (2014). Social Policy Preferences and Party Choice in the 2011 Swiss Elections. Swiss Political Science Review, 20(4), 590-611. doi:10.1111/spsr.12115

Gamson, W. A., \& Modigliani, A. (1989). Media Discourse and Public-Opinion on NuclearPower - A Constructionist Approach. American Journal of Sociology, 95(1), 1-37. doi:10.1086/229213

Gerth, M. A., \& Siegert, G. (2012). Patterns of Consistence and Constriction: How News Media Frame the Coverage of Direct Democratic Campaigns. American Behavioral Scientist, 56(3), 279-299. doi:10.1177/0002764211426326

Greenacre, M., \& Blasius, J. (2006). Multiple Correspondence Analysis and Related Methods. Boca Raton, FL: Chapman \& Hall.

Haenggli, R. (2012). Key Factors in Frame Building: How Strategic Political Actors Shape News Media Coverage. American Behavioral Scientist, 56(3), 300-317. doi:10.1177/0002764211426327

Haenggli, R., \& Kriesi, H. (2010). Political Framing Strategies and Their Impact on Media Framing in a Swiss Direct-Democratic Campaign. Political Communication, 27(2), 141-157. doi:10.1080/10584600903501484

Hallin, D. C., \& Mancini, P. (2004). Comparing Media Systems. Three Models of Media and Politics (L. W. Bennet \& R. M. Entman Eds.). Cambridge: Cambridge University Press.

Igartua, J. J., Cheng, L., \& Muniz, C. (2005). Framing Latin America in the Spanish press: A cooled down friendship between two fraternal lands. Communications-European Journal of Communication Research, 30(3), 359-372. doi:10.1515/comm.2005.30.3.359

Iyengar, S. (1991). Is Anyone Responsible? How Television Frames Political Issues. Chicago: University of Chicago Press.

Kaplan, R. L. (2002). Politics and the American Press: The Rise of Objectivity, 1865-1920. In. Cambridge: Cambridge University Press.

Kriesi, H. (1992). Öffentlichkeit und soziale Bewegung in der Schweiz - ein Musterfall? In B. Schäfer (Ed.), Lebensverhältnisse und soziale Konflikte im neuen Europa (pp. 576585). Frankfurt: Campus.

Lecheler, S., de Vreese, C., \& Slothuus, R. (2009). Issue Importance as a Moderator of Framing Effects. Communication Research, 36(3), 400-425. doi:10.1177/0093650209333028

Lecheler, S., \& de Vreese, C. H. (2011). Getting Real: The Duration of Framing Effects. Journal of Communication, 61(5), 959-U248. doi:10.1111/j.1460-2466.2011.01580.x

Lecheler, S., \& de Vreese, C. H. (2013). What a Difference a Day Makes? The Effects of Repetitive and Competitive News Framing Over Time. Communication Research, 40(2), 147-175. doi:10.1177/0093650212470688 
Lengauer, G., Esser, F., \& Berganza, R. (2012). Negativity in political news: A review of concepts, operationalizations and key findings. Journalism, 13(2), 179-202. doi:10.1177/1464884911427800

Linder, W. (2010). Swiss democracy. Possible solutions to conflict in multicultural society (3 ed.). Basingstoke: Palgrave/Macmillan.

Maier, J., \& Rittberger, B. (2008). Shifting Europe's boundaries: Mass media, public opinion and the enlargement of the EU. European Union Politics, 9(2), 243-267. doi:10.1177/1465116508089087

Meyer, R. E., \& Hoellerer, M. A. (2010). Meaning Structures in a Contested Issue Field: A Topographic Map of Shareholder Value in Austria. Academy of Management Journal, 53(6), 1241-1262. doi:10.5465/AMJ.2010.57317829

Nelson, T. E., \& Kinder, D. R. (1996). Issue frames and group-centrism in American public opinion. Journal of Politics, 58(4), 1055-1078. doi:10.2307/2960149

Neuman, W., Just, M., \& Crigler, A. (1992). Common knowledge: News and the construction of political meaning Chicago, IL: University of Chicago Press.

Saguy, A. C. (2002). Sexual Harassment in the News: The United States and France. The Communication Review, 5(2), 109-141. doi:10.1080/10714420212478

Sciarini, P., \& Tresch, A. (2009). A Two-Level Analysis of the Determinants of Direct Democratic Choices in European Immigration and Foreign Policy in Switzerland. European Union Politics, 10(4), 456-481. doi:10.1177/1465116509346388

Semetko, H. A., \& Valkenburg, P. M. (2000). Framing European politics: A content analysis of press and television news. Journal of Communication, 50(2), 93-109. doi:10.1093/joc/50.2.93

Sparrow, B. H. (1999). Uncertain Guardians: The News Media as a Political Institution. Baltimore: Johns Hopkins University Press.

Stromback, J., \& Nord, L. W. (2006). Do politicians lead the tango? - A study of the relationship between Swedish journalists and their political sources in the context of election campaigns. European Journal of Communication, 21(2), 147-164. doi:10.1177/0267323105064043

Trechsel, A. (1995). Clivages en Suisse. Analyse des impacts relatifs des clivages sur l'électorat suisse lors des élections fédérales. Genève.

Tresch, A. (2009). Politicians in the Media: Determinants of Legislators' Presence and Prominence in Swiss Newspapers. International Journal of Press-Politics, 14(1), 6790. doi:10.1177/1940161208323266

Van Gorp, B. (2007). The constructionist approach to framing: Bringing culture back in. Journal of Communication, 57(1), 60-78. doi:10.1111/j.1460-2466.2006.00329.x

Vatter, A. (1994). Der EWR-Entscheid: Kulturelle Identität, rationales Kalkül oder struktureller Kontext? Schweizerische Zeitschrift für Soziologie, 20(1), 15-42.

Vliegenthart, R., \& van Zoonen, L. (2011). Power to the frame: Bringing sociology back to frame analysis. European Journal of Communication, 26(2), 101-115. doi:10.1177/0267323111404838

Maier, J., \& Rittberger, B. (2008). Shifting Europe's boundaries: Mass media, public opinion and the enlargement of the EU. European Union Politics, 9(2), 243-267.

Nelson, T. E., \& Kinder, D. R. (1996). Issue frames and group-centrism in American public opinion. Journal of Politics, 58(4), 1055-1078.

Neuman, W., Just, M., \& Crigler, A. (1992). Common knowledge: News and the construction of political meaning Chicago, IL: University of Chicago Press.

Saguy, A. C. (2002). Sexual Harassment in the News: The United States and France. The Communication Review, 5(2), 109-141. 
Sciarini, P., \& Tresch, A. (2009). A Two-Level Analysis of the Determinants of Direct Democratic Choices in European Immigration and Foreign Policy in Switzerland. European Union Politics, 10(4), 456-481.

Semetko, H. A., \& Valkenburg, P. M. (2000). Framing European politics: A content analysis of press and television news. Journal of Communication, 50(2), 93-109.

Stromback, J., \& Nord, L. W. (2006). Do politicians lead the tango? - A study of the relationship between Swedish journalists and their political sources in the context of election campaigns. European Journal of Communication, 21(2), 147-164.

Trechsel, A. (1995). Clivages en Suisse. Analyse des impacts relatifs des clivages sur l'électorat suisse lors des élections fédérales. Genève.

Tresch, A. (2009). Politicians in the Media: Determinants of Legislators' Presence and Prominence in Swiss Newspapers. International Journal of Press-Politics, 14(1), 6790.

Van Gorp, B. (2007). The constructionist approach to framing: Bringing culture back in. Journal of Communication, 57(1), 60-78.

Vatter, A. (1994). Der EWR-Entscheid: Kulturelle Identität, rationales Kalkül oder struktureller Kontext? Schweizerische Zeitschrift für Soziologie, [The EEA decision: Cultural identity, rational calculation or structural context? Swiss Journal of Sociology] 20(1), 15-42.

Vliegenthart, R., \& van Zoonen, L. (2011). Power to the frame: Bringing sociology back to frame analysis. European Journal of Communication, 26(2), 101-115.

Figure 1: Multiple Correspondence Map 


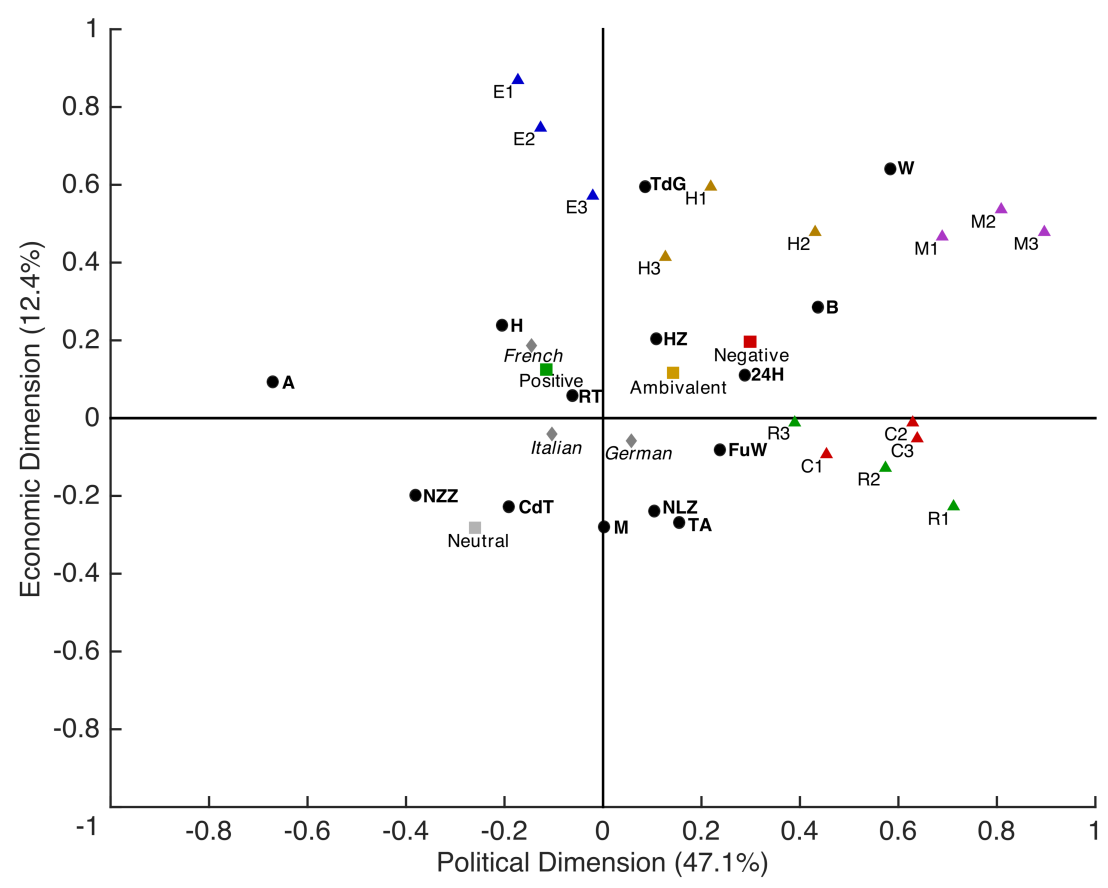

Notes: All media outlets are designated by dots, cultural areas by rhombs, tonalities by squares and items of generic frames by triangles. Items of generic frames are abbreviated according to Table 1 and outlets as follows: $24 \mathrm{H}=24 \mathrm{Heures}$,

A=L'Agefi, B=Blick, CdT=Corriere del Ticino, FuW=Finanz und Wirtschaft, H=L'Hebdo, HZ=Handelszeitung, M=Le Matin, NLZ=Neue Luzerner Zeitung, NZZ=Neue Zürcher Zeitung, RT=La Regione Ticino, TA=Tages Anzeiger, $\mathrm{TdG}=$ Tribune de Genève and $\mathrm{W}=$ Weltwoche.

Table 1: Attitudes of Swiss Political Parties on the Issue

\begin{tabular}{lccccccc}
\hline & \multicolumn{2}{c}{ Positive } & \multicolumn{2}{c}{ Negative } & \multicolumn{2}{c}{ Ambivalent } \\
\cline { 2 - 7 } & $\mathrm{N}$ & $\%$ & $\mathrm{~N}$ & $\%$ & \multicolumn{2}{c}{$\mathrm{N}$} & $\%$ \\
\hline Swiss People's Party & 2 & 1.6 & 118 & 91.5 & 9 & 7.0 \\
Social Democratic Party & 69 & 48.6 & 26 & 18.3 & 47 & 33.1 \\
Liberal Party & 108 & 45.8 & 20 & 8.5 & 108 & 45.8 \\
Christian Democratic Party & 38 & 48.7 & 21 & 26.9 & 19 & 24.4 \\
Conservative Democratic Party & 24 & 77.4 & 1 & 3.2 & 6 & 19.4 \\
\hline
\end{tabular}

Figure 2: Dynamic Correspondence Map 


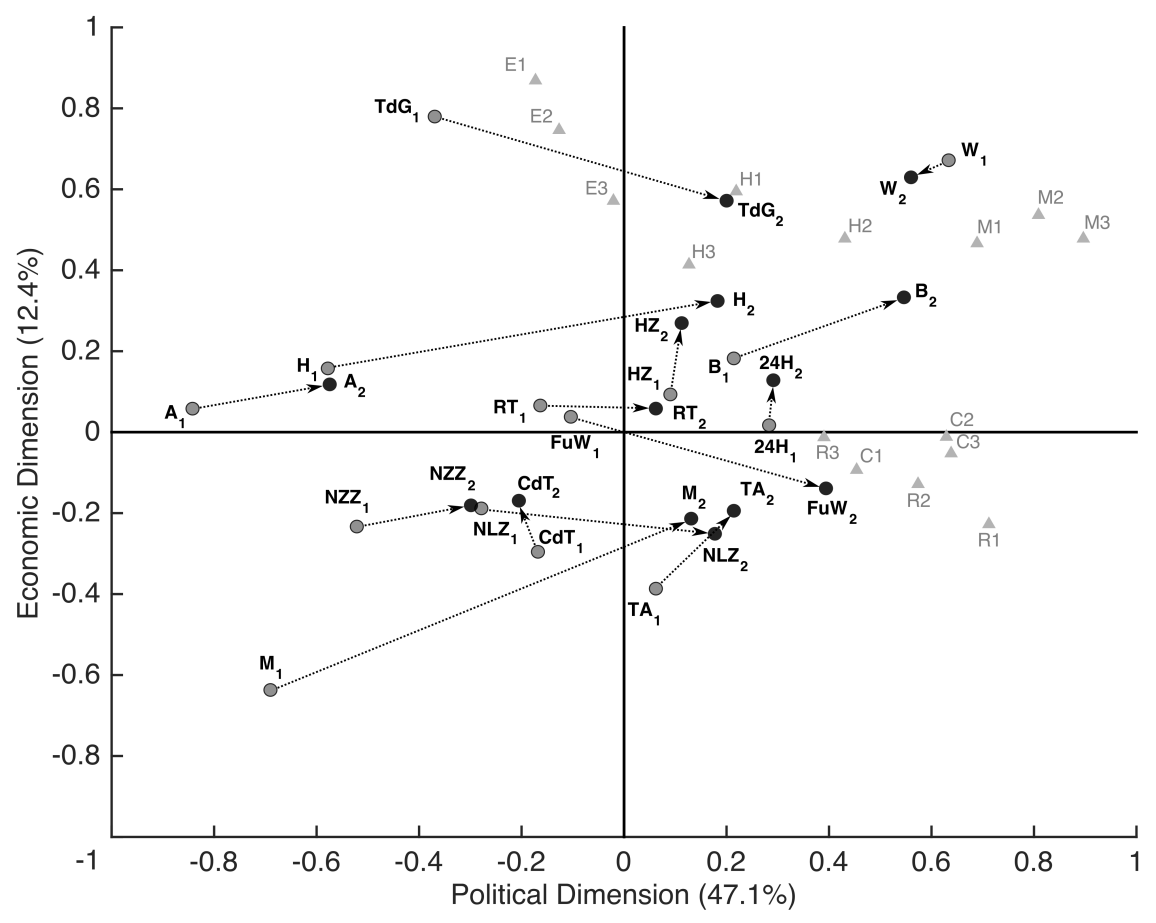

Notes: All media outlets are designated by dots and items of generic frames by triangles. The same abbreviations are employed as in Figure 1, where the subscripts 1 and 2 for outlets denote the period before and respectively after February 2012. Arrows further visualize the direction and intensity of the shift in the framing practices of the respective outlets.

Table 2: Tonalities of the News Stories Before and After State's Involvement

\section{News Stories (N) Positive Negative Ambivalent Neutral}

\begin{tabular}{lccccc}
\hline $\begin{array}{l}\text { Period I } \\
\text { Feb. 2008 - Jan. 2012 }\end{array}$ & 413 & $27.40 \%$ & $18.40 \%$ & $13.80 \%$ & $40.40 \%$ \\
$\begin{array}{l}\text { Period II } \\
\text { Feb. 2012 - Sept. 2013 }\end{array}$ & 762 & $17.80 \%$ & $41.50 \%$ & $8.00 \%$ & $32.70 \%$ \\
\hline
\end{tabular}

